\title{
Developing operations strategies - reassessing the strength and importance of competitive operations priorities for South African businesses
}

\author{
L.P. Krüger \\ College of Economic and Management Sciences, \\ School of Management Sciences, Department of Business Management, \\ UNISA, Pretoria 0003, Republic of South Africa \\ krugelp@unisa.ac.za
}

Received June 2010

\begin{abstract}
Operations strategy issues (irrespective of whether they concern content and/or process aspects) still generate considerable interest and attention from researchers and business practitioners alike. While the underlying theory is seemingly well documented and supposedly well understood at this time, the practical implementation concerns through empirical studies of application in various countries arguably still need greater clarity and appreciation. In this regard, a follow-up study of a 1996 research project was conducted in 2009 of a sample of the largest 500 companies in South Africa (including the JSE-listed top 100). The empirical study again focused on the relative strength and importance of five competitive operations priorities (COPs), namely cost, quality, speed, dependability and flexibility, within the context of improving national and international competitiveness. The results suggest that South African businesses, which have developed an operations capability that simultaneously offers higher quality products and/or services at a lower cost and on a more dependable basis than its competitors do, hold the most promise for success in the future business environment locally and internationally.
\end{abstract}

*To whom all correspondence should be addressed.

\section{Introduction}

Interest ${ }^{1}$ in the role of the operations strategy in business (i.e. the formulation of content) and in the way in which this will be pursued (i.e. the process of the implementation of intent) is still as prevalent and contemporary as before. The content and process issues of developing operations strategies find their expression in what Slack, Chambers and Johnston (2007) refer to as the "performance objectives" of the operation. These objectives typically comprise some combination of improved quality, lower cost, faster speed, greater dependability and/or greater flexibility. When closely aligned with customer/client needs, the performance objectives represent the competitive operations priorities (COP) which the business will attempt to pursue.

Individual businesses will typically put different emphasis on one or more combinations of such desired capability

\footnotetext{
${ }^{1}$ Despite some 25 years that has passed since the early "pioneers" such as Hayes and Wheelwright (1984) and Hill (1985) first started writing about the then referred to manufacturing strategy (operations strategy today), the topic still attracts interest amongst academia, researchers and business practitioners. The number of requests received from respondents wishing to obtain a copy of the results of the research partly bears testament to this, as does the frequent conference tracks that are included in production/operations strategy.
}

traits given the interpretation of their particular customer/clients' needs. However, collectively (similar to a "thermometer-type" reading), the companies within a country (when sampled together) may offer a broad-stroke suggestion of where they think they ought to be in the future to be able to compete against both national and international competitors.

\section{Background: The 1996 research project - South African strategic manufacturing priorities (SMPs)}

More than thirteen years ago, Krüger (1997) conducted an empirical study in which the opinions of management of so-called "large" South African manufacturers (those employing more than 500 employees) were solicited. Respondents were asked to indicate the operations factors or priorities (termed strategic manufacturing priorities [SMPs] for this study) that they believed to be important given South Africa's imminent ${ }^{2}$ re-emergence and normalisation into global competitive business markets. These manufacturers indicated the most important operations factors or priorities as (1) high quality, (2) low cost, (3) high dependability, (4) high speed, and (5) high flexibility.

\footnotetext{
2 This was signalled by the end of apartheid with the first all-inclusive, free and democratic elections towards the end of April 1994.
} 
Moreover, they felt their current performance levels needed to improve between 20 and $30 \%$ in all of the aforementioned performance areas. Regarding their competing in international markets - as compared to only competing in national markets - they conceded that, on average, they needed to improve with an additional $5 \%$ or more.

In June 2009, a longitudinal, follow-up study was commissioned $^{3}$ with the purpose of comparing the results of the earlier study alluded to above. The main aim was to broaden the focus of the study to include non-manufacturers (i.e. service providers). This dual focus was in response to the increasing growth of this particular segment within the South African economy, now reflecting a similar trend to developed economies of the world. Furthermore, an explicit objective was to research the impact of politically inspired so-called "transformational policies" such as BEE (black economic empowerment) and AA (affirmative action) on the competitiveness of both traditional manufacturers and increasingly important service providers. However, this aspect is not discussed in this article, as more research is required and is currently underway.

\section{Literature review: update}

The theoretical background of the research, which provided the platform for the 1996 project, is well documented in a comprehensive research report and summarised in the above-mentioned article by Krüger (1997). The primary focus points of the literature review provided in that article are as follows (Note: the references in this section are not repeated at the end of this article, as they can be traced from the references first used.):

- $\quad$ The emergence of manufacturing-based strategies and their potential to enhance the competitive capabilities of the business as a whole. Reference was made to the Hayes and Wheelwright (1984) four-stage model in the evolution of the strategic role of manufacturing as well as contributions by other authors in this regard. Amongst these, reference was made to Crowe and Nuño (1991), Zahra and Das (1993), Miller and Roth (1994), Feurer and Charharbaghi (1995), and Slack, Chambers, Harland, Harrison and Johnston (1995).

- The use of the term "strategic manufacturing priorities" in the particular study and the identification of such representative operations capabilities, namely, quality, cost, speed, dependability and flexibility. The performance objectives of Slack et al. (1995) were selected in due consideration of the views of and suggestions by Garvin (1993), Vickery, Droge and Markland (1993), Miller et al. (1994), and Schlie and Goldhar (1995).

- $\quad$ The general acceptance of the need to make trade-offs between different strategic manufacturing priorities due to differences in customer requirements, competitor

\footnotetext{
${ }^{3}$ Ms Ilja de Boer was appointed as the research consultant to assist with the design and development of the electronic questionnaire, the administration of the survey, data capturing and statistical analysis.
}

actions and the particular stage of the product or service in its life cycle. The relative importance of the strategic manufacturing priorities can be determined by distinguishing between "order-winning" and "qualifying" factors as suggested by Hill (1985). Arguments were considered both against the practice of making trade-offs (Schonberger \& Knod (1991); and Collins \& Schmenner (1993)) and in favour of the need for it (Crowe et al. (1991), Garvin (1993), Hayes \& Pisano (1994), Russell \& Taylor (1995) and Slack et al. (1995)).

During the course of reviewing the literature published from 1996 to 2009, a number of interesting and important developments were noted in the context of operations strategy, which offered significant insights:

- Continued interest in the research topic (operations strategy) is evident from articles appearing in journals and other publications.

- The "sophistication" of research conducted in this field has improved quite considerably, accompanied by a significant increase in empirical testing of various theoretical models of operations strategy for casual interrelationships. Examples include tracking of the development and rigorous testing of various manufacturing-strategy models such as the trade-off (Noble, 1995) versus the cumulative (or sand-cone) models (Nakane, 1986) and their relevance to the improvement of business performance or ROA (return on assets); the use of specific measures such as the first pass yield for quality and the percentage of sales for cost, rather than other "subjective" indices or constructed scales of relative performance; the clarification of and relationship between "resources", "capability" and "competencies" whereby operations capabilities are defined as combinations of acquired competencies and resources (Corbett \& Claridge, 2002).

- The number of reported "new" linkages with other theoretical constructs, not only within the operations domain but also in the context of financial, marketing and supply chain management. This has effectively enlarged the scope of the research topic thereby offering the potential for better understanding the dynamic interor cross-functional interactions, such as the explicit link to the benchmarking technique and the prominent attention received by the Manufacturing Futures Survey. This survey has been conducted every two years since 1981 amongst the major industrialised countries including South Africa, Australia, China, Korea, Europe, Japan, the USA, et cetera, and it is coordinated by the Boston University, USA (Corbett, 1998). In addition, the broader focus on the "overall" business performance, the alignment of marketing and manufacturing (operations) strategies with one another, and the matching imperative for competitive priorities that cannot be dissimilar or disparate from customers' demand, are all "new" points of interest (Berry, Hill \& Klompmaker, 1999). Yet another example is the development of global strategies and internationalisation of emerging MNEs (multinational 
enterprises) from developing economies like South Africa, based on their exploitation of competencies developed within the country (home grown - refer to competitive firm-specific advantages) and on their transfer of said competencies, initially to other developing countries, and later to developed markets by maintaining a strong performance management culture (Klein \& Wöcke, 2007).

- Reaffirmation of the main theoretical focus points (see previous paragraph) from which the conceptual framework for the initial research was developed improves the validity of the framework. For example, a "thermometer reading", so to speak, is taken of the current level of strength and importance of certain competitive operations priorities at different businesses (so-called "macro-level" benchmarking) in order to determine not only how a company compares with its competitors but also which companies are demonstrating the best performance in similar fields, or which companies are engaged in similar activities (Corbett, 1998). The necessity to accept trade-offs is also an important factor. (Corbett, (1998) warns that companies may try to excel in all aspects or may want to improve across too many fronts, and that they may end up excelling at nothing and showing no improvement.) Finally, the discussion under this heading turns to the manufacturing (operations) strategy to be expressed in competitive terms such as cost, quality, dependability and flexibility, thus conforming to the Hill (1993) framework of criteria, which "enables a company to win orders against competitors", and to the criterion that "a company must meet for a customer to even consider it as a possible supplier" (Berry et al., 1999).

- The possible link of the specific research focus to some broader or more general concepts, including competiveness and sustainability, which (according to Walker \& Minnitt, 2006) indicate certain niche competencies and expertise developed by companies in specific industry clusters.

- The continued apparent lack of universal consensus on the use of terminology, specific performance factors or objectives, methods of measurement, levels of acceptable to superior performance, and models of operations strategy. However, the concept of justification for the operations-strategy focus is, in the first place, a bit disappointing. It may be a distraction to discourage in-depth research in the field concerned for better understanding, for instance, terminology differences such as "manufacturing capability", specific performance factors selected such as innovation in lieu of speed, the arguments for and against the cumulative versus sand-cone model, the conclusion with regard to improved business performance that "no evidence was found for the sand-cone model in capability development as well as no evidence that the cumulative module gives better ROA", et cetera (Corbett \& Claridge, 2002). The term "competitive operations priorities" (COP), which was used in the 2009 survey, was derived from the concept of competitive priorities
(Evans \& Collier, 2007:122) and was adapted to reflect an operations-management focus. These two authors suggest that all organisations are concerned with building and sustaining a competitive advantage in their market(s) and generally have five competitive priorities, namely cost, quality, time, flexibility and innovation.

- Conducting similar studies in other areas of specialisation (e.g. Hipkin (2004) on managers' perceptions of technology strategies in developing countries, with specific reference to South Africa) and "new" ideas which came to mind or were encountered to advance the research in operations strategy (e.g. the development of a four-quadrant matrix for the alignment of marketing and manufacturing strategies (Berry et al., 1999), and the importance-control framework used by Hipkin (2004) to identify important and significant issues or factors that could affect the formulation and implementation of technology strategies, measured against management's ability and power to exercise "control", that is, direct, regulate or influence them).

The research conducted by Hipkin (2004), specifically on determining technology strategies in developing countries, shows a number of similarities with this study, which are noteworthy for comparative purposes:

- Context. Both studies are conducted in South Africa, which is a developing country facing the challenges of globalisation, and which has undergone unique political transformation and social restructuring in the last fifteen years. The developed world markets are characterised by more rigorous quality standards, highly demanding customers, shorter product life cycles, greater product diversity, and a more fragmented and ever-increasing environmental consciousness. The history of South Africa is unique and presents unprecedented challenges due to the extremely prominent role of government (past and present) and intense politicisation of all conceivable aspects of personal, community and business life (e.g. affirmative action, employment equity, and employee empowerment).

- Level of investigation. Both studies are conducted at the higher, strategic level of business where management not only must familiarise themselves with the importance of contemporary issues in the business environment but are also responsible for taking such measures that are deemed necessary to "control" the impact of such factors.

- Focus of interest. Both studies focus on the key business requisite of competitiveness in local (domestic) and international markets. They also both consider a dynamic time frame from a current position of strength and importance to a future point.

- $\quad$ Core theoretical foundation. Both studies reflect on the progressive development and role of the operations strategy (towards the highest level of the Hayes \& Wheelwright framework where the competitive strategy of the business lies with the manufacturing capability), 
the distinction in importance between so-called "order qualifying" and "order winning" criteria (Hill), and the selection and ranking of competitive priorities (such as quality, conformance to specifications, reliability, flexibility, innovative capacity, financial viability, and cost-effective production processes) that a particular firm will use to compete and develop its longer-term competencies.

However, the Hipkin (2004) study considered the development of technology strategy within the context of (1) the prevailing economic conditions and political issues; (2) human resource management and capacity; (3) technical ability; (4) operations competence and financial viability; (5) knowledge level and expertise; (6) short-term versus long-term impact; and (7) cultural (anthropological) differences in outlook and behaviour.

\section{Research design and methodology}

\section{Conceptual research framework}

The previous conceptual research framework that was used in the study by Krüger (1997) was again adopted as the basis for the new study, but it was amended to allow for the enlarged scope. Figure 1 illustrates the amended conceptual research framework named version 2. The framework has five major points of focus that entail determining:

1. the current contribution (and future potential) of the operations capability of the company to achieve longterm, superior business performance and success (Response options: Yes/Not sure/No).

2. the perceived current strength and/or weakness of South African companies with regard to the prelisted competitive operations priorities (high quality, low cost, high speed, flexibility and dependability) for competing against national and international competitors (Response range: Very strong, Strong, Neutral, Weak, Very weak).

3. the perceived future value or importance of South African companies with regard to the prelisted competitive operations priorities for competing against national and international competitors (Response range: Not important, Good to have, Necessary, Important, Very important).

4. the areas or competitive operations priorities in which these companies possibly need to shift their emphasis and/or improve on their current performance levels in order to better compete against national and international competitors (Comparison: Current strength versus future importance (national) and current strength versus future importance (international)).

5. the impact of transitional policies on the competitive operations priorities of South African companies in terms of their "general feeling" towards such practices and probable influence that BEE/AA, et cetera, may have on South African companies' ability to (i) attain targets, (ii) to improve on their competitive operations priorities, and (iii) their ability to compete nationally and internationally.

\section{Research population}

The research population encompassed individuals who were either the CEO/MD or the Director: Operations, or somebody who held a similar senior managerial position inside the company. The personal contact details (name, address and e-mail) of the targeted individuals were obtained from the top 100 listed JSE companies (based on turnover) and also a further selection of the top 500 of South Africa's best companies (2008 edition). The South African companies were conducting business in any one or more of the following industries: food, beverage and tobacco; textiles, clothing and footwear; pharmaceuticals; wood products and furniture; paper and printing; chemicals and petroleum products; communication and telephone; hotel, catering and restaurants; medical service, hospitals and clinics; security services and armed response; entertainment including sport and theatre; nonmetallic minerals; basic metal products; fabricated metal products; transport equipment; electronics and electrical equipment; other machinery and equipment; electricity, water and gas utilities; professional services such as lawyers and doctors; transport such as air, sea, road and rail; plant, animal parks and zoos; trading, warehousing and wholesale; property; financial services; mining, and other.

\section{Data-collection procedures}

Whereas the 1996 study used printed questionnaires that were posted to the physical addresses of the CEOs of some 500 companies listed as manufacturers, the 2009 study was more "progressive in nature" and kept up with recent IT advances. On-line surveys have become popular due to their many advantages such as speed of delivery, quick response, convenience of response, simplicity in data capturing, more reliable data analysis, et cetera (there may be inherent problem areas to consider). As with any survey (postal or now online), measures must be put into place to ensure the reliability and validity of data. To improve reliability, the online survey was first sent electronically to 10 of the envisaged 100 participants, who were then asked to complete the questionnaire, but also to provide their comments on the suitability, clarity, et cetera, of the survey instrument. Note: In all cases where electronic surveys had been sent to respondents, the individual e-mail addresses were obtained and verified before the questionnaire was dispatched. A total of 144 e-mails were sent out to the targeted research population. In the end, 104 completed responses were solicited (36 were online and a further 68 were telephonic interviews), which presents a very good response rate of $72 \%$. The telephonic interview route was later taken because of the low online response rate and because of the relatively small sample size. The low online response rate is possibly due to time limitations (the respondents work in listed companies where time is normally at a premium) and/or respondent fatigue (many complained that they were inundated with a number of online surveys at any point in time) and/or it could be 
because of a genuine non-interest in the topic of the research.

To gain further insight into possible reasons and/or motivations for responses, fifteen in-depth interviews were conducted with individuals who had not previously participated in the electronic online survey or telephonic interviews. A combination of quantitative and qualitative instruments to solicit and analyse responses is used quite frequently and has advantages in terms of improved reliability and validity of results (Walker \& Minnitt, 2006).

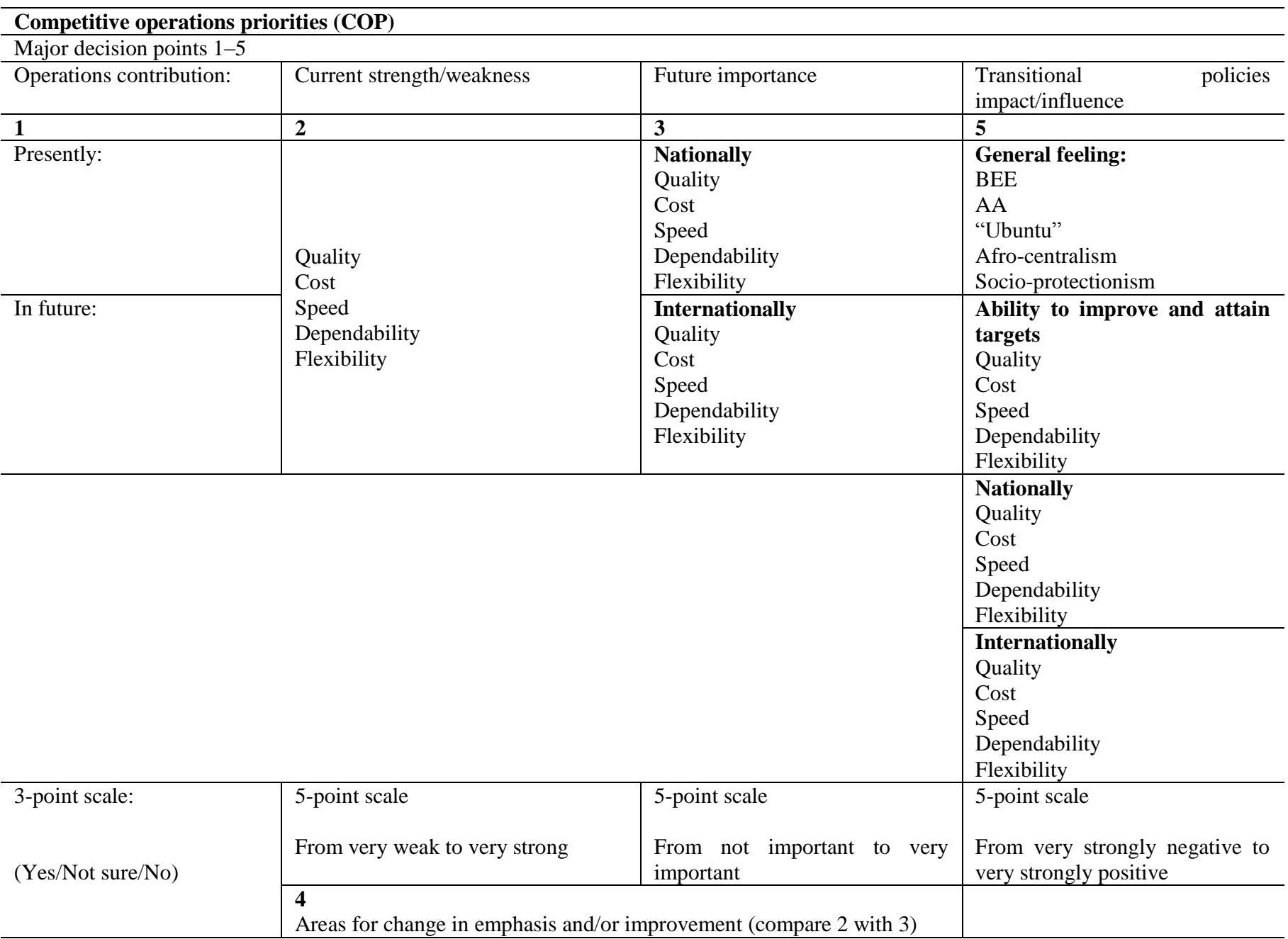

Figure 1: Conceptual research framework: version 2

\section{Research results and discussion ${ }^{4}$}

\section{Part I: Results of the 2009 empirical study}

The first aspect to be determined was the current contribution of the operations capability towards achieving long-term, superior business performance and success. The results gained from the survey are presented in Table 1 . A total of $85,6 \%$ of the respondents believed that the operations strategy of their company definitely contributed to its long-term superior business performance and success.

\footnotetext{
${ }^{4}$ The results of the fifteen in-depth interviews conducted are not included with these results and are not separately reported on, as no significant differences were found, though additional information was gathered regarding the respondents' motivation and reasons for their answers. This will prove most valuable in the consideration of the fifth major focus point - see section 4.1 - which is not addressed in this article, however.
}

A small percentage $(2.9 \%)$ of the respondents completely disagreed with this view, while $11.5 \%$ were unsure.

The second aspect to be determined was the future importance of the operations capability for the purposes of improving the national and international competitive position of the business. The results gained from the survey are presented in Table 2. A large majority of the respondents (97\%) believed that the operations capabilities of their company would become more important in order to compete better against national and international competitors in the future. None of the respondents disagreed completely, while $7 \%$ were unsure.

The third point of focus was to determine the current strength and/or weakness of competitive operations priorities that enhance/erode the company's ability to compete nationally. Based on the calculated weighted average scores, the ranking order (Table 3) for the current 
strength and/or weakness of the listed competitive operations priorities, considered in terms of national competiveness (in order of greater strength), was: (1) high quality; (2) high dependability; (3) high speed; (4) high flexibility; and (5) low cost. Note: This ranking order is derived purely mathematically and it is not necessarily statistically significant.

Next, the fourth point of focus was to determine the current strength and/or weakness of competitive operations priorities that enhance/erode the company's ability to compete internationally. Based on the calculated weighted average scores, the ranking order (Table 4) for the current strength and/or weakness of the listed competitive operations priorities, considered in terms of international competitiveness (in order of greater strength), was: (1) high dependability; (2) high quality; (3) high flexibility; (4) high speed; and (5) low cost. Note: This ranking order is derived purely mathematically and it is not necessarily statistically significant.

Table 1: Frequency table of contributions of operations strategy towards the company's long-term, superior business performance and success

\begin{tabular}{l|c|c|c|c}
\hline \multicolumn{1}{c|}{ Contribution } & Yes & Not sure & No & Total N \\
\hline $\mathrm{N}$ & 89 & 12 & 3 & 104 \\
\hline$\% \mathrm{~T}$ & $85,6 \%$ & $11,5 \%$ & $2,9 \%$ & $100 \%$ \\
\hline Average & & & & 1,173 \\
\hline Standard deviation & & & & 0,450 \\
\hline
\end{tabular}

Table 2: Frequency table of future importance of operations capabilities to better compete nationally and internationally

\begin{tabular}{l|c|c|c|c}
\hline \multicolumn{1}{c|}{ Contribution } & Yes & Not sure & No & Total N \\
\hline $\mathrm{N}$ & 97 & 7 & 0 & 104 \\
\hline$\% \mathrm{~T}$ & $93,3 \%$ & $6,7 \%$ & $0,0 \%$ & $100 \%$ \\
\hline Average & & & & 1,067 \\
\hline Standard deviation & & & 0,221 \\
\hline
\end{tabular}

Table 3: Current strength and/or weakness in competitive operations priorities to compete nationally

\begin{tabular}{|c|c|c|c|c|c|c|c|c|c|c|}
\hline \multirow[b]{2}{*}{ Current strength } & \multicolumn{2}{|c|}{ Quality } & \multicolumn{2}{|c|}{ Cost } & \multicolumn{2}{|c|}{ Speediness } & \multicolumn{2}{|c|}{ Dependability } & \multicolumn{2}{|c|}{ Flexibility } \\
\hline & $\mathbf{N}$ & $\% \mathrm{~T}$ & $\mathbf{N}$ & $\% \mathrm{~T}$ & $\mathbf{N}$ & $\% \mathrm{~T}$ & $\mathbf{N}$ & $\% \mathrm{~T}$ & $\mathbf{N}$ & $\% \mathrm{~T}$ \\
\hline Very weak & 0 & 0 & 0 & 0 & 0 & 0 & 0 & 0 & 0 & 0 \\
\hline Weak & 0 & 0 & 25 & 24,3 & 7 & 6,7 & 0 & 0 & 14 & 13,5 \\
\hline Neutral & 14 & 13,6 & 32 & 31,1 & 41 & 39,4 & 10 & 9,7 & 40 & 38,5 \\
\hline Strong & 44 & 42,7 & 37 & 35,9 & 33 & 31,7 & 60 & 58,3 & 28 & 26,9 \\
\hline Very strong & 45 & 43,7 & 9 & 8,7 & 23 & 22,1 & 33 & 32 & 22 & 21,2 \\
\hline Total & 103 & 100 & 103 & 100 & 104 & 100 & 103 & 100 & 104 & 100 \\
\hline Mean & \multicolumn{2}{|c|}{4,3} & \multicolumn{2}{|c|}{3,29} & \multicolumn{2}{|c|}{3,69} & \multicolumn{2}{|c|}{4,22} & \multicolumn{2}{|c|}{3,56} \\
\hline Standard deviation & \multicolumn{2}{|c|}{0,694} & \multicolumn{2}{|c|}{0,931} & \multicolumn{2}{|c|}{0,899} & \multicolumn{2}{|c|}{0,606} & \multicolumn{2}{|c|}{0,969} \\
\hline P-value CS & \multicolumn{2}{|c|}{0,5107} & \multicolumn{2}{|c|}{0,1897} & \multicolumn{2}{|c|}{0,2926} & \multicolumn{2}{|c|}{0,5427} & \multicolumn{2}{|c|}{0,2563} \\
\hline $\mathrm{P}$-value CW & \multicolumn{2}{|c|}{0,0005} & \multicolumn{2}{|c|}{0,760} & \multicolumn{2}{|c|}{0,0287} & \multicolumn{2}{|c|}{0,0001} & \multicolumn{2}{|c|}{0,0496} \\
\hline Rank & \multicolumn{2}{|c|}{2} & \multicolumn{2}{|c|}{5} & \multicolumn{2}{|c|}{3} & \multicolumn{2}{|c|}{1} & \multicolumn{2}{|c|}{4} \\
\hline
\end{tabular}

$\mathrm{N}=$ frequency; \% $\mathrm{T}$ = percentage of total; Rank = ranking order; P-value $\mathrm{CS}=$ probability of falling within the range of strong/very strong; $\mathrm{P}$ value $\mathrm{CW}=$ probability of falling within the range of weak/very weak 
Table 4: Current strength and/or weakness of competitive operations priorities internationally

\begin{tabular}{|c|c|c|c|c|c|c|c|c|c|c|}
\hline \multirow[b]{2}{*}{ Current strength } & \multicolumn{2}{|c|}{ Quality } & \multicolumn{2}{|c|}{ Cost } & \multicolumn{2}{|c|}{ Speediness } & \multicolumn{2}{|c|}{ Dependability } & \multicolumn{2}{|c|}{ Flexibility } \\
\hline & $\mathbf{N}$ & $\% \mathrm{~T}$ & $\mathbf{N}$ & $\% \mathbf{T}$ & $\mathbf{N}$ & $\% \mathbf{T}$ & $\mathbf{N}$ & $\% \mathrm{~T}$ & $\mathbf{N}$ & $\% \mathrm{~T}$ \\
\hline Very weak & 0 & 0 & 5 & 4,9 & 0 & 0 & 0 & 0 & 0 & 0 \\
\hline Weak & 0 & 0 & 23 & 22,5 & 9 & 8,8 & 5 & 4,9 & 9 & 8,8 \\
\hline Neutral & 28 & 27,2 & 20 & 19,6 & 26 & 25,5 & 20 & 19,4 & 25 & 24,5 \\
\hline Strong & 42 & 40,8 & 34 & 33,3 & 41 & 40,2 & 39 & 37,9 & 39 & 38,2 \\
\hline Very strong & 33 & 32 & 20 & 19,6 & 26 & 25,5 & 39 & 37,9 & 29 & 28,4 \\
\hline Total & 103 & 100 & 102 & 100 & 102 & 100 & 103 & 100 & 102 & 100 \\
\hline Mean & \multicolumn{2}{|c|}{4,05} & \multicolumn{2}{|c|}{3,40} & \multicolumn{2}{|c|}{3,82} & \multicolumn{2}{|c|}{4,09} & \multicolumn{2}{|c|}{3,86} \\
\hline Standard deviation & \multicolumn{2}{|c|}{0,772} & \multicolumn{2}{|c|}{1,180} & \multicolumn{2}{|c|}{0,916} & \multicolumn{2}{|c|}{0,876} & \multicolumn{2}{|c|}{0,934} \\
\hline P-value CS & \multicolumn{2}{|c|}{0,4166} & \multicolumn{2}{|c|}{0,2180} & \multicolumn{2}{|c|}{0,3233} & \multicolumn{2}{|c|}{0,3915} & \multicolumn{2}{|c|}{0,3293} \\
\hline $\mathrm{P}$-value CW & \multicolumn{2}{|c|}{0,0039} & \multicolumn{2}{|c|}{0,0967} & \multicolumn{2}{|c|}{0,0224} & \multicolumn{2}{|c|}{0,0083} & \multicolumn{2}{|c|}{0,0221} \\
\hline Rank & \multicolumn{2}{|c|}{1} & \multicolumn{2}{|c|}{5} & \multicolumn{2}{|c|}{4} & \multicolumn{2}{|c|}{2} & \multicolumn{2}{|c|}{3} \\
\hline
\end{tabular}

$\mathrm{N}$ = frequency; \% $\mathrm{T}$ = percentage of total; Rank = ranking order; P-value CS = probability of falling within the range of very strong/strong; Pvalue $\mathrm{CW}=$ probability of falling within the range of weak/very weak

The fifth point of focus was to make a comparison of the current strength and/or weakness of competitive priorities to compete nationally versus internationally. The results are shown in Table 5. Significant differences (gaps) were indicated for: (1) flexibility (companies believe their flexibility equips them to compete better in the international than the national market); (2) quality (companies believe their quality is better received in the national than in the international market); and (3) speed (companies believe they respond with greater speed internationally than nationally) see Graph 1.

With the sixth point of focus, the future importance of competitive operations priorities, considered as enabling greater competitiveness in national markets, was considered. The results are presented in Table 6.

Based on the calculated weighted average scores, the ranking order for the future importance assigned to the listed competitive operations priorities in a national context (in order of greater importance) was: (1) high quality; (2) high dependability; (3) low cost; (4) high speed; and (5) high flexibility. Note: This ranking order is derived purely mathematically and it is not necessarily statistically significant.

With the seventh point of focus, the future importance of competitive operations priorities, considered as enabling greater competitiveness in international markets, was considered. The results are presented in table 7 .

Based on the calculated weighted average scores, the ranking order for the future importance assigned to the listed competitive operations priorities internationally (in order of greater importance) was: (1) high quality; (2) high dependability; (3) low cost; (4) high flexibility; and (5) high speed. Note: This ranking order is derived purely mathematically and it is not necessarily statistically significant.

The eighth point of focus was to make a comparison of the future importance of enabling better national compared to international competitiveness. The results are shown in table 8. Significant differences (gaps) were indicated for (1) high flexibility (companies believe that they will need to be even more flexible in the future in order to be more competitive in the international market); and (2) high speed (companies believe they will need to respond with even greater speed in the future in order to be more competitive in the national market) - see Graph 2.

The ninth point of focus was to make a comparison of the current strength and/or weakness with future importance, considered in both instances as enabling better competitiveness in a national context. The results are shown in Table 9. Significant gaps were indicated for (1) low cost (companies believe they must put in a greater effort to lower their cost to compete better in a national context); (2) higher quality (companies should improve their quality in a similar way); (3) high speed (companies should also improve their speed in terms of responding to customers); and (4) high flexibility (companies believe their flexibility is not quite yet what is required in a national context) - see Graph 3. 
Table 5: Wilcoxon matched-pairs signed ranks rests: movement between decision points : Current strength and/or weakness

\begin{tabular}{|c|c|c|c|c|c|}
\hline $\begin{array}{l}\text { National } \\
\text { vs } \\
\text { International }\end{array}$ & $\begin{array}{l}\text { Quality (N) } \\
\leftarrow \text { Quality (I) }\end{array}$ & $\begin{array}{l}\text { Cost }(\mathrm{N}) \\
\leftarrow \operatorname{Cost}(\mathrm{I})\end{array}$ & $\begin{array}{l}\text { Speediness }(\mathrm{N}) \leftarrow \\
\text { Speediness }(\mathrm{I})\end{array}$ & $\begin{array}{l}\text { Dependability }(\mathrm{N}) \leftarrow \\
\text { Dependability (I) }\end{array}$ & $\begin{array}{l}\text { Flexibility (N) } \\
\leftarrow \text { Flexibility (I) }\end{array}$ \\
\hline P-value & 0,0011 & 0,2703 & 0,0437 & 0,199 & $<0,0001$ \\
\hline z-value & $-3,277$ & $-1,143$ & $-2,035$ & $-1,305$ & $-4,432$ \\
\hline Exact or approximate P-value? & $\begin{array}{c}\text { Gaussian } \\
\text { approximation }\end{array}$ & $\begin{array}{c}\text { Gaussian } \\
\text { approximation }\end{array}$ & $\begin{array}{c}\text { Gaussian } \\
\text { approximation }\end{array}$ & $\begin{array}{c}\text { Gaussian } \\
\text { approximation }\end{array}$ & $\begin{array}{c}\text { Gaussian } \\
\text { approximation }\end{array}$ \\
\hline $\mathrm{P}$-value summary & $* *$ & $\mathrm{~ns}$ & $*$ & Ns & $* * *$ \\
\hline $\begin{array}{l}\text { Are medians significantly } \\
\text { different? }(\mathrm{P}<0.05)\end{array}$ & Yes & No & Yes & No & Yes \\
\hline One- or two-tailed P-value? & Two-tailed & Two-tailed & Two-tailed & Two-tailed & Two-tailed \\
\hline $\begin{array}{l}\text { Sum of positive, negative } \\
\text { ranks }\end{array}$ & $581,-160$ & $571,-808$ & $494,-884$ & $456,-285$ & $117,-703$ \\
\hline Sum of signed ranks (W) & 421 & -237 & -390 & 171 & -586 \\
\hline
\end{tabular}

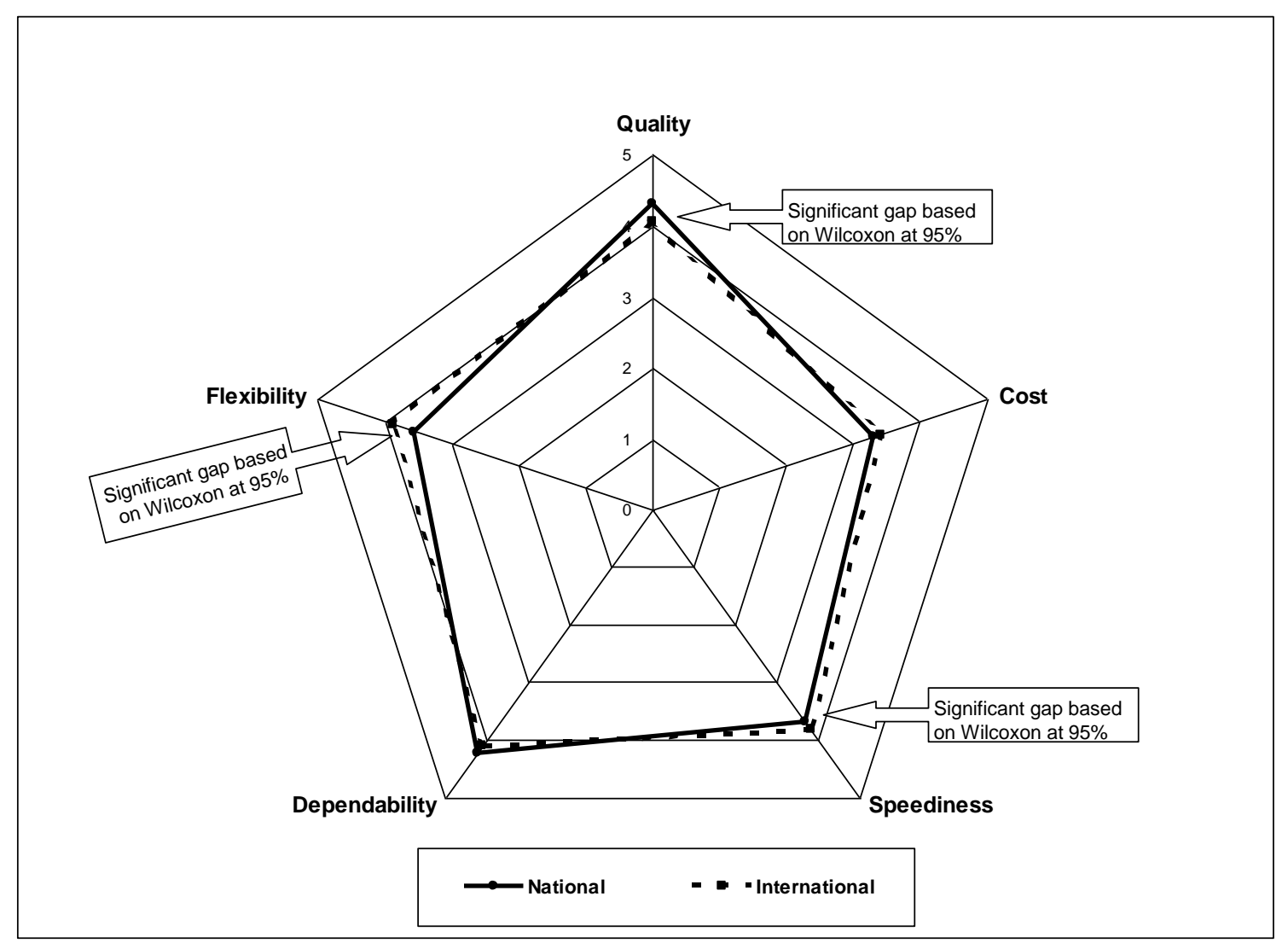

Graph 1: Current strength: National compared to international 
Table 6: Future importance of competitive operations priorities to compete better nationally

\begin{tabular}{|c|c|c|c|c|c|c|c|c|c|c|}
\hline & \multicolumn{2}{|c|}{ Quality } & \multicolumn{2}{|c|}{ Cost } & \multicolumn{2}{|c|}{ Speediness } & \multicolumn{2}{|c|}{ Dependability } & \multicolumn{2}{|c|}{ Flexibility } \\
\hline & $\mathbf{N}$ & $\% \mathrm{~T}$ & $\mathbf{N}$ & $\% \mathbf{T}$ & $\mathbf{N}$ & $\% \mathrm{~T}$ & $\mathbf{N}$ & $\% \mathrm{~T}$ & $\mathbf{N}$ & $\% \mathrm{~T}$ \\
\hline Not important & 0 & $0 \%$ & 0 & 05 & 0 & $0 \%$ & 0 & $0 \%$ & 0 & $0 \%$ \\
\hline Good to have & 5 & $4,81 \%$ & 9 & $8,65 \%$ & 0 & $0,00 \%$ & 1 & $0,96 \%$ & 16 & $15,38 \%$ \\
\hline Necessary & 0 & $0 \%$ & 17 & $16,35 \%$ & 25 & $24,04 \%$ & 12 & $11,54 \%$ & 23 & $22,12 \%$ \\
\hline Important & 14 & $13,46 \%$ & 28 & $26,92 \%$ & 46 & $44,23 \%$ & 43 & $41,35 \%$ & 34 & $32,69 \%$ \\
\hline Very important & 85 & $81,73 \%$ & 50 & $48,08 \%$ & 33 & $31,73 \%$ & 48 & $46,15 \%$ & 31 & $29,81 \%$ \\
\hline Total & 104 & $100 \%$ & 104 & $100 \%$ & 104 & $100 \%$ & 104 & $100 \%$ & 104 & $100 \%$ \\
\hline Mean & \multicolumn{2}{|c|}{4,721} & \multicolumn{2}{|c|}{4,144} & \multicolumn{2}{|c|}{4,077} & \multicolumn{2}{|c|}{4,327} & \multicolumn{2}{|c|}{3,769} \\
\hline Standard dev & \multicolumn{2}{|c|}{0,7031} & \multicolumn{2}{|c|}{0,9894} & \multicolumn{2}{|c|}{0,7464} & \multicolumn{2}{|c|}{0,7165} & \multicolumn{2}{|c|}{1,045} \\
\hline P-value CS & \multicolumn{2}{|c|}{0,5017} & \multicolumn{2}{|c|}{0,3644} & \multicolumn{2}{|c|}{0,4330} & \multicolumn{2}{|c|}{0,5022} & \multicolumn{2}{|c|}{0,2931} \\
\hline $\mathrm{P}$-value $\mathrm{CW}$ & \multicolumn{2}{|c|}{0,0001} & \multicolumn{2}{|c|}{0,0144} & \multicolumn{2}{|c|}{0,0027} & \multicolumn{2}{|c|}{0,0006} & \multicolumn{2}{|c|}{0,0412} \\
\hline Rank & \multicolumn{2}{|c|}{1} & \multicolumn{2}{|c|}{3} & \multicolumn{2}{|c|}{4} & \multicolumn{2}{|c|}{2} & \multicolumn{2}{|c|}{5} \\
\hline
\end{tabular}

$\mathrm{N}=$ frequency; \% $\mathrm{T}$ = percentage of total; Rank = ranking order; P-value $\mathrm{CS}$ = probability of falling within the range of strong/very strong; $\mathrm{P}$ value $\mathrm{CW}=$ probability of falling within the range of weak/very weak

Table 7: Future importance of competitive operations priorities to compete better internationally

\begin{tabular}{|c|c|c|c|c|c|c|c|c|c|c|}
\hline & \multicolumn{2}{|c|}{ Quality } & \multicolumn{2}{|r|}{ Cost } & \multicolumn{2}{|c|}{ Speediness } & \multicolumn{2}{|c|}{ Dependability } & \multicolumn{2}{|c|}{ Flexibility } \\
\hline & $\mathbf{N}$ & $\% \mathrm{~T}$ & $\mathbf{N}$ & $\% \mathrm{~T}$ & $\mathbf{N}$ & $\% \mathrm{~T}$ & $\mathbf{N}$ & $\% \mathbf{T}$ & $\mathbf{N}$ & $\% \mathrm{~T}$ \\
\hline Not important & 0 & 0 & 0 & $0 \%$ & 0 & $0 \%$ & 0 & $0 \%$ & 4 & $0 \%$ \\
\hline Good to have & 0 & $0 \%$ & 10 & $9,8 \%$ & 0 & $0,00 \%$ & 4 & $3,88 \%$ & 26 & $3,88 \%$ \\
\hline Necessary & 5 & $4,85 \%$ & 3 & $2,94 \%$ & 37 & $35,92 \%$ & 11 & $10,68 \%$ & 30 & $25,24 \%$ \\
\hline Important & 10 & $9,71 \%$ & 45 & $44,12 \%$ & 41 & $39,81 \%$ & 35 & $33,98 \%$ & 43 & $29,13 \%$ \\
\hline Very important & 88 & $85,43 \%$ & 44 & $43,14 \%$ & 25 & $24,27 \%$ & 53 & $51,46 \%$ & 31 & $41,75 \%$ \\
\hline Total & 103 & $100 \%$ & 102 & $100 \%$ & 103 & $100 \%$ & 103 & $100 \%$ & 103 & $100 \%$ \\
\hline Mean & \multicolumn{2}{|r|}{4,806} & \multicolumn{2}{|r|}{4,206} & \multicolumn{2}{|r|}{3,883} & \multicolumn{2}{|r|}{4,33} & \multicolumn{2}{|c|}{4,087} \\
\hline Standard dev & \multicolumn{2}{|r|}{0,506} & \multicolumn{2}{|c|}{0,9048} & \multicolumn{2}{|r|}{0,7708} & \multicolumn{2}{|r|}{0,8211} & \multicolumn{2}{|c|}{0,9086} \\
\hline P-value CS & \multicolumn{2}{|r|}{0,5937} & \multicolumn{2}{|c|}{0,4000} & \multicolumn{2}{|r|}{0,3660} & \multicolumn{2}{|r|}{0,4489} & \multicolumn{2}{|c|}{0,3807} \\
\hline $\mathrm{P}$-value CW & \multicolumn{2}{|r|}{0,0000} & \multicolumn{2}{|c|}{0,0072} & \multicolumn{2}{|r|}{0,0072} & \multicolumn{2}{|r|}{0,0022} & \multicolumn{2}{|c|}{0,0105} \\
\hline Rank & \multicolumn{2}{|r|}{1} & \multicolumn{2}{|c|}{3} & \multicolumn{2}{|r|}{5} & \multicolumn{2}{|r|}{2} & \multicolumn{2}{|c|}{4} \\
\hline
\end{tabular}

$\mathrm{N}=$ frequency; \% $\mathrm{T}$ = percentage of total; Rank = ranking order; P-value CS = probability of falling within the range of strong/very strong; $\mathrm{P}$ value $\mathrm{CW}=$ probability of falling within the range of weak/very weak

Table 8 Wilcoxon matched-pairs signed ranks rests: movement between decision points : Future importance

\begin{tabular}{|c|c|c|c|c|c|}
\hline $\begin{array}{l}\text { National } \\
\text { Versus } \\
\text { International }\end{array}$ & $\begin{array}{c}\text { Quality (I) } \\
\leftarrow \text { Quality (N) }\end{array}$ & $\begin{array}{l}\operatorname{Cost}(I) \\
\leftarrow \operatorname{Cost}(N)\end{array}$ & $\begin{array}{c}\text { Speediness }(\mathbf{I}) \\
\leftarrow \text { Speediness }(\mathbf{N})\end{array}$ & $\begin{array}{c}\text { Dependability (I) } \\
\leftarrow \text { Dependability (N) }\end{array}$ & $\begin{array}{c}\text { Flexibility (I) } \\
\leftarrow \text { Flexibility }(\mathrm{N})\end{array}$ \\
\hline Mean Rank & $\begin{array}{c}3 \\
6,67\end{array}$ & $\begin{array}{l}20,10 \\
21,71\end{array}$ & $\begin{array}{l}15,78 \\
16,78\end{array}$ & $\begin{array}{c}20,5 \\
12,38\end{array}$ & $\begin{array}{c}13 \\
17,67\end{array}$ \\
\hline +Ranks & 5 & 19 & 26 & 10 & 5 \\
\hline -Ranks & 6 & 24 & 7 & 21 & 30 \\
\hline Ties & 93 & 60 & 71 & 73 & 69 \\
\hline $\mathrm{N}$ & 104 & 103 & 104 & 104 & 104 \\
\hline z-value & $-1,173$ & $-0,946$ & $-3,017$ & $-0,691$ & $-4,209$ \\
\hline P-value & 0,2121 & 0,345 & 0,0029 & 0,5497 & $<0,0001$ \\
\hline$P$ value summary & Ns & $\mathrm{ns}$ & $* *$ & ns & $* * *$ \\
\hline $\begin{array}{l}\text { Are medians significant } \\
\text { different? }(\mathrm{P}<0,05)\end{array}$ & No & No & Yes & No & Yes \\
\hline One- or two-tailed P-value? & Two-tailed & Two-tailed & Two-tailed & Two-tailed & Two-tailed \\
\hline $\begin{array}{l}\text { Sum of positive, negative } \\
\text { ranks }\end{array}$ & $15,00,-40,00$ & $\begin{array}{l}382,0,- \\
521,0\end{array}$ & $410,5,-117,5$ & $205,0,-260,0$ & $65,00,-530,0$ \\
\hline Sum of signed ranks (W) & -25 & -139 & 293 & -55 & -465 \\
\hline
\end{tabular}




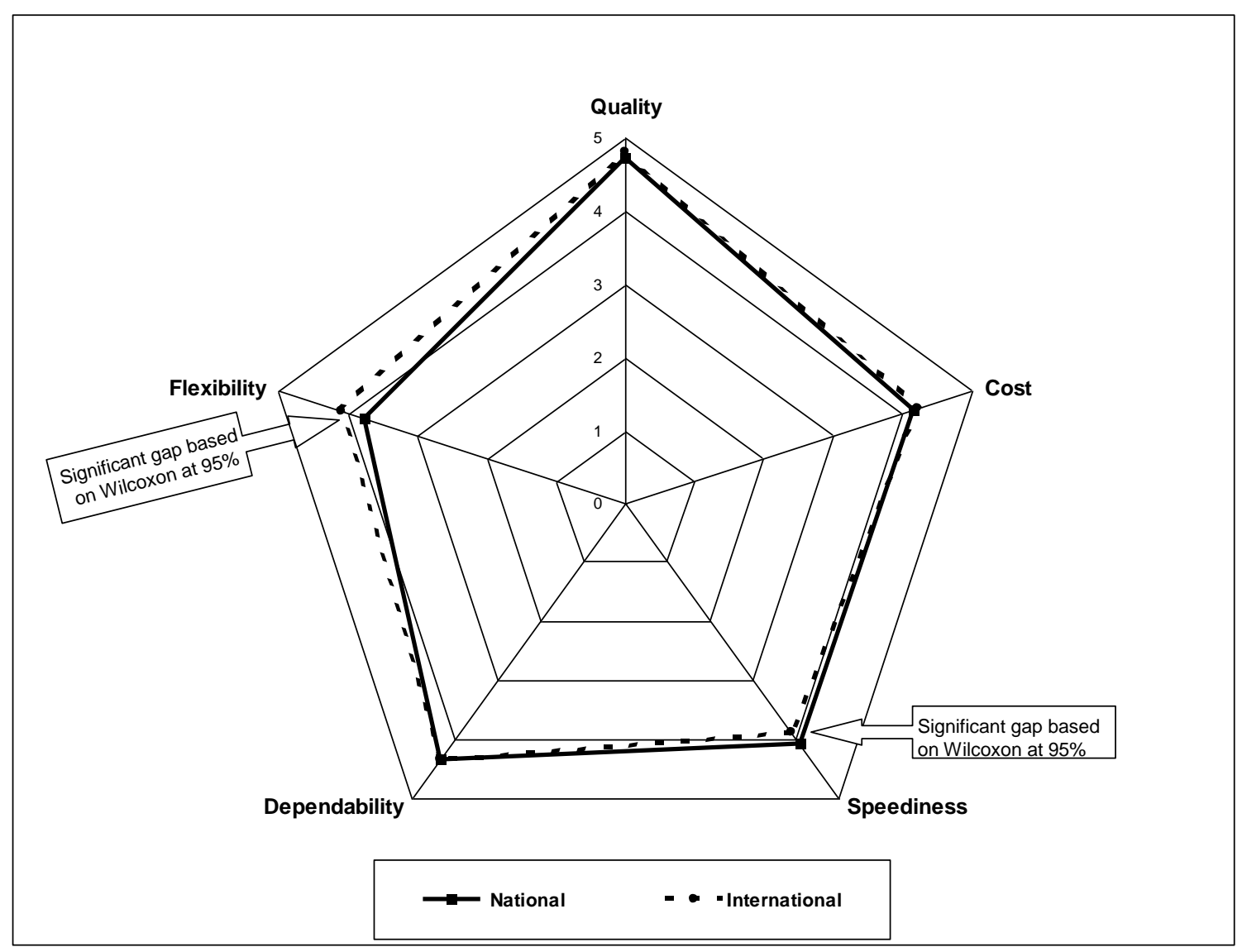

Graph 2: Future importance national vs international

Table 9:Wilcoxon matched-pairs signed ranks rests: movement between decision points : NATIONAL

\begin{tabular}{|c|c|c|c|c|c|}
\hline $\begin{array}{l}\text { Current strength }(\mathrm{CS}) \\
\text { versus } \\
\text { Future importance (FI) }\end{array}$ & $\begin{array}{c}\text { Quality (I) } \\
\leftarrow \text { Quality (N) }\end{array}$ & $\begin{array}{c}\operatorname{Cost}(I) \\
\leftarrow \operatorname{Cost}(N)\end{array}$ & $\begin{array}{c}\text { Speediness }(I) \\
\leftarrow \text { Speediness }(\mathbf{N})\end{array}$ & $\begin{array}{c}\text { Dependability (I) } \\
\leftarrow \text { Dependability }(\mathbf{N})\end{array}$ & $\begin{array}{c}\text { Flexibility (I) } \\
\leftarrow \text { Flexibility (N) }\end{array}$ \\
\hline Mean Rank & $\begin{array}{l}48,00 \\
23,00\end{array}$ & $\begin{array}{l}19,50 \\
40,60\end{array}$ & $\begin{array}{l}21,44 \\
24,53\end{array}$ & $\begin{array}{l}30,63 \\
23,25\end{array}$ & $\begin{array}{l}29,06 \\
34,71\end{array}$ \\
\hline -Ranks & 5 & 14 & 8 & 19 & 25 \\
\hline +Ranks & 45 & 58 & 39 & 32 & 39 \\
\hline Ties & 53 & 31 & 57 & 52 & 40 \\
\hline $\mathrm{N}$ & 103 & 103 & 104 & 103 & 104 \\
\hline z-value & $-3,965$ & $-5,983$ & $-4,407$ & $-0,789$ & $-2,251$ \\
\hline P-value & $<0,0001$ & $<0,0001$ & $<0,0001$ & 0,4328 & 0,0246 \\
\hline P-value summary & $* * *$ & $* * *$ & $* * *$ & ns & $*$ \\
\hline $\begin{array}{l}\text { Are medians signif. } \\
\text { different? }(\mathrm{P}<0.05)\end{array}$ & Yes & Yes & Yes & No & Yes \\
\hline One- or two-tailed P-value? & Two-tailed & Two-tailed & Two-tailed & Two-tailed & Two-tailed \\
\hline $\begin{array}{l}\text { Sum of positive, negative } \\
\text { ranks }\end{array}$ & $240,-1035$ & $273,-2355$ & $172,-957$ & $582,-744$ & $727,-1354$ \\
\hline Sum of signed ranks (W) & -795 & -2082 & -785 & -162 & -627 \\
\hline
\end{tabular}




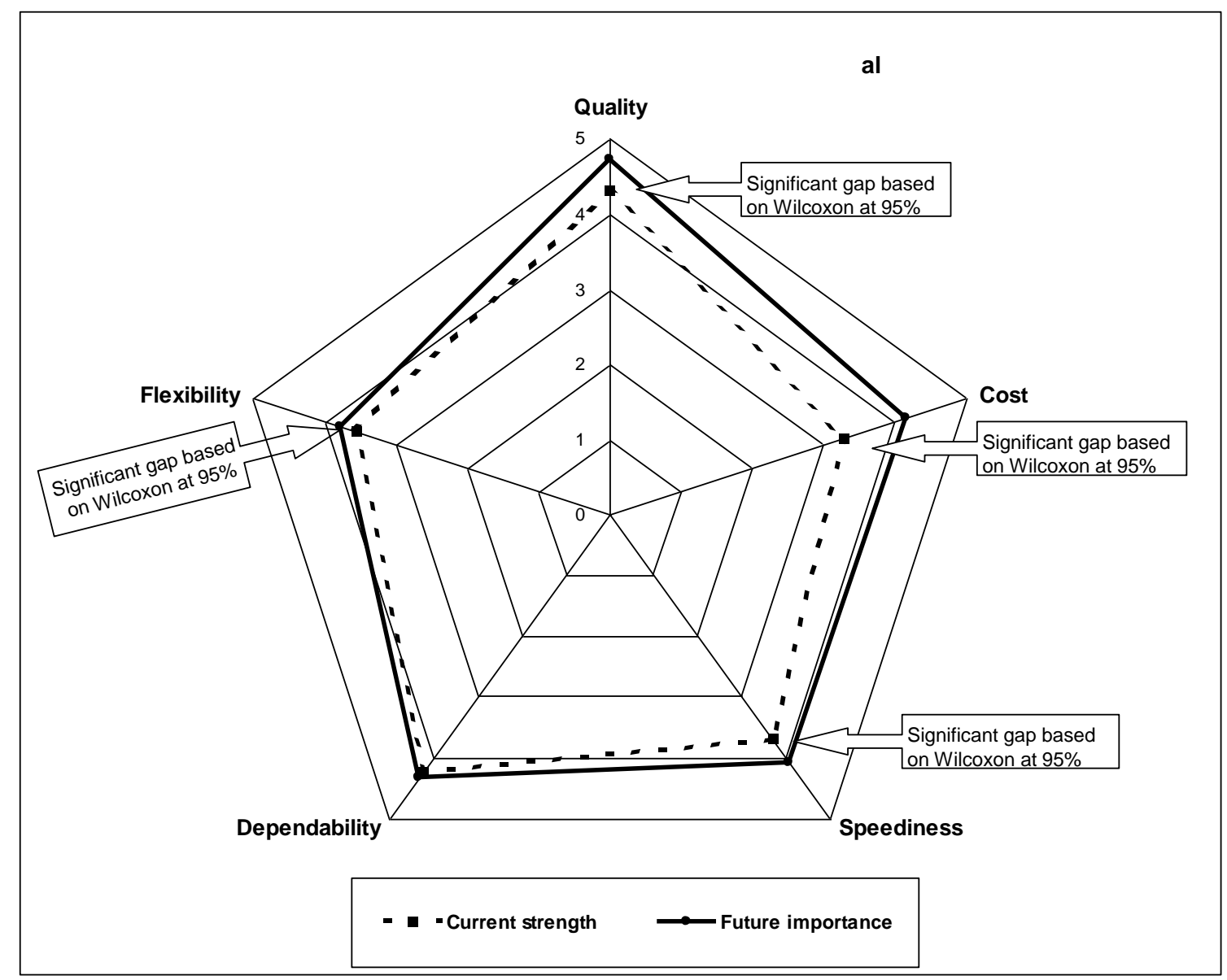

Graph 3: Current strength vs future importance national

The tenth point of focus was to make a comparison of current strength and/or weakness with future importance, considered in both instances as enabling better competitiveness in an international context. The results are shown in Table 10. Significant gaps were indicated for (1) low cost (companies believe they must put in a greater effort to lower their cost in order to compete better in an international context); (2) higher quality (companies, should improve their quality in a similar way); and (3) high flexibility (companies should also become more flexible to compete better internationally). (Note: This result is the opposite of what has been found in the case of competing nationally, where companies felt they were offering too much flexibility - see Graph 4.)

Part II: Comparison between the results of the 1996 and the 2009 survey

Since it is unlikely that the same respondents participated in both the 1996 and the 2009 surveys, any comparison between these surveys should be considered with due caution (both in terms of reliability and validity of data used). However, from a "macro" view, both surveys took a "thermometer-type reading" of a pool of some 100 large South African businesses, and such a comparison may indicate possible improvements and/or shifts in priorities over the thirteen-year interval between the surveys.

Here, the first point of focus was to determine the current strength and/or weakness in competitive operations priorities, considered in combination as enabling better national and international competition. The results between the 1996 and 2009 surveys are shown in Table 11. Improvements were observed in all five of the competitive operations priorities. The improvements in speediness, flexibility and dependability were statistically significant see Graph 5.

The second point of focus here was to determine the future importance considered as enabling better competitiveness in the national context. The results between the 1996 and 2009 surveys are shown in Table 12. Increased importance was observed for high quality* and greater speed, but decreased importance for lower cost*, greater dependability and high flexibility - see Graph 6.

*Statistically significant result

Lastly, the third point of focus here was to determine the future importance considered as enabling better competitiveness in the international context. The results between the 1996 and 2009 surveys are shown in Table 13. Increased importance was observed for high quality and high flexibility but decreased importance for lower cost*, greater dependability* and greater speed* ${ }^{*}$ see Graph 7.

*Statistically significant result 
Table 10: Wilcoxon matched-pairs signed ranks rests: movement between decision points: International

\begin{tabular}{|c|c|c|c|c|c|}
\hline $\begin{array}{l}\text { Current strength }(\mathrm{CS}) \text { versus } \\
\text { Future importance (FI) }\end{array}$ & $\begin{array}{l}\text { Quality (CS) } \\
\leftarrow \text { Quality (FI) }\end{array}$ & $\begin{array}{l}\text { Cost }(\mathbf{C S}) \\
\leftarrow \operatorname{Cost}(\mathbf{F I})\end{array}$ & $\begin{array}{l}\text { Speediness (CS) } \\
\leftarrow \text { Speediness (FI) }\end{array}$ & $\begin{array}{l}\text { Dependability (CS) } \\
\leftarrow \text { Dependability (FI) }\end{array}$ & $\begin{array}{l}\text { Flexibility (CS) } \\
\leftarrow \text { Flexibility (FI) }\end{array}$ \\
\hline Mean Rank & $\begin{array}{l}28,50 \\
32,77 \\
\end{array}$ & $\begin{array}{l}30,39 \\
37,38 \\
\end{array}$ & $\begin{array}{l}34,48 \\
34,51 \\
\end{array}$ & $\begin{array}{l}34,25 \\
25,25 \\
\end{array}$ & $\begin{array}{l}25,28 \\
26,33 \\
\end{array}$ \\
\hline +Ranks & 60 & 57 & 37 & 38 & 35 \\
\hline -Ranks & 4 & 14 & 31 & 17 & 16 \\
\hline Ties & 39 & 30 & 34 & 48 & 51 \\
\hline $\mathrm{N}$ & 103 & 101 & 102 & 103 & 102 \\
\hline z-value & $-6,430$ & $-5,001$ & $-0,687$ & $-1,635$ & $-2,582$ \\
\hline P-value & $<0,0001$ & $<0,0001$ & 0,494 & 0,103 & 0,01 \\
\hline $\mathrm{P}$-value summary & $* * *$ & $* * *$ & $\mathrm{~ns}$ & ns & $* *$ \\
\hline $\begin{array}{l}\text { Are medians signif. different? } \\
(\mathrm{P}<0,05)\end{array}$ & Yes & Yes & No & No & Yes \\
\hline One- or two-tailed P-value? & Two-tailed & Two-tailed & Two-tailed & Two-tailed & Two-tailed \\
\hline Sum of positive, negative ranks & $114,-1966$ & $426,-2131$ & $1069,-1277$ & $581,-960$ & $405,-922$ \\
\hline Sum of signed ranks (W) & -1852 & -1705 & -208 & -379 & -517 \\
\hline
\end{tabular}

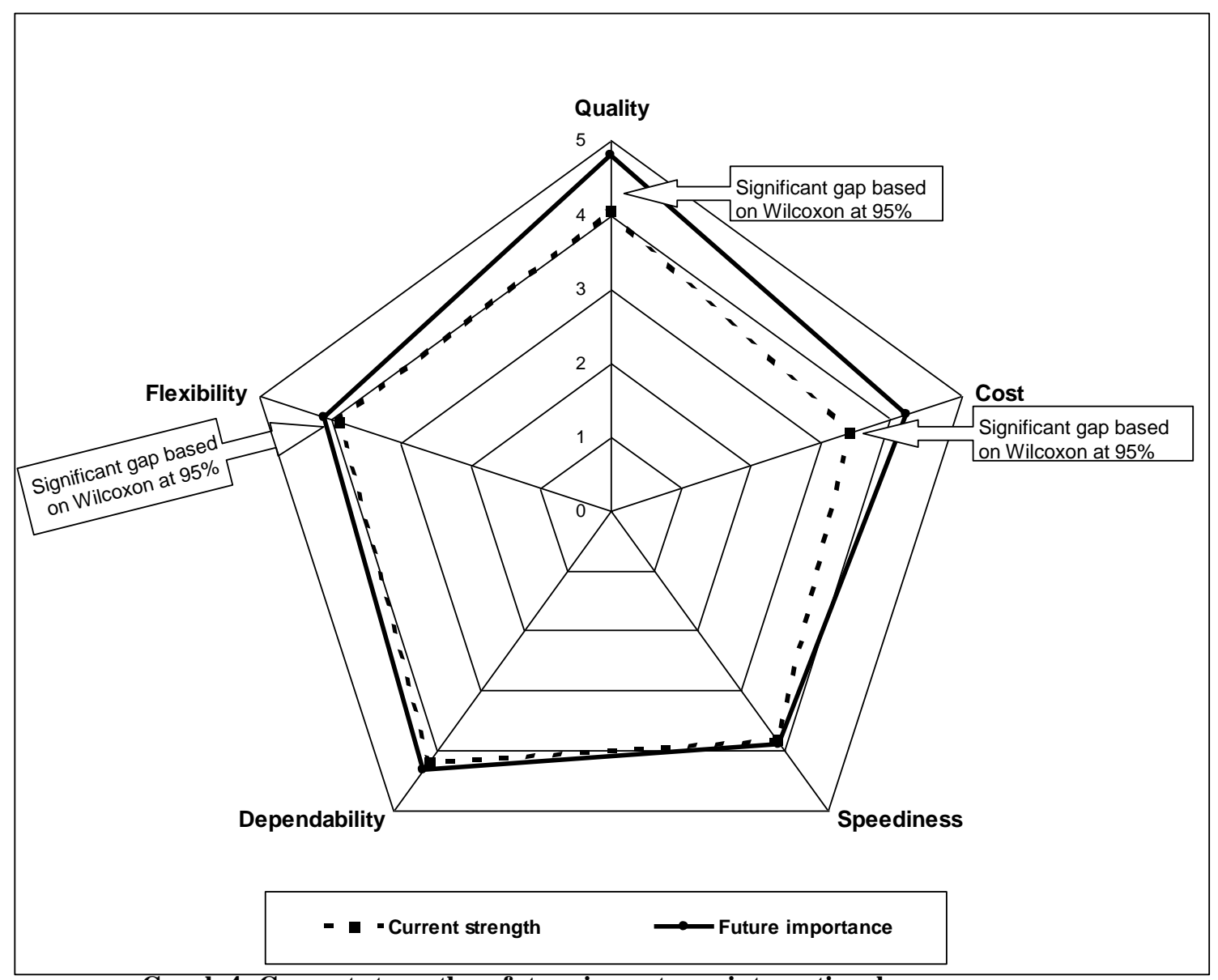

Graph 4: Current strength vs future importance international 
Table 11: Current strength and/or weakness 1996 vs 2009

\begin{tabular}{|c|c|c|c|c|c|c|c|c|c|c|}
\hline & \multicolumn{2}{|c|}{ Quality } & \multicolumn{2}{|c|}{ Cost } & \multicolumn{2}{|c|}{ Speediness } & \multicolumn{2}{|c|}{ Dependability } & \multicolumn{2}{|c|}{ Flexibility } \\
\hline & 1996 & 2009 & 1996 & 2009 & 1996 & 2009 & 1996 & 2009 & 1996 & 2009 \\
\hline Total & 130 & 104 & 134 & 104 & 132 & 104 & 134 & 104 & 132 & 104 \\
\hline Mean & 4,032 & 4,1135 & 3,090 & 3,298 & 3,220 & 3,721 & 3,790 & 4,115 & 3,303 & 3,673 \\
\hline Standard dev & 0,710 & 0,659 & 0,950 & 0,920 & 0,890 & 0,850 & 0,800 & 0,660 & 0,930 & 0,650 \\
\hline Rank & 1 & 1 & 5 & 5 & 4 & 3 & 2 & 2 & 3 & 4 \\
\hline Gap & \multicolumn{2}{|c|}{$+0,100$} & \multicolumn{2}{|c|}{$+0,210$} & \multicolumn{2}{|c|}{$+0,500$} & \multicolumn{2}{|c|}{$+0,330$} & \multicolumn{2}{|c|}{$+0,370$} \\
\hline \begin{tabular}{l}
\multicolumn{2}{l}{ Significance } \\
based on
\end{tabular} & \multicolumn{2}{|c|}{ No } & \multicolumn{2}{|c|}{ No } & \multicolumn{2}{|c|}{ Yes } & \multicolumn{2}{|c|}{ Yes } & \multicolumn{2}{|c|}{ Yes } \\
\hline
\end{tabular}

$+=$ belief that current strength is more important in 2009 than $1996 ;-=$ belief that current strength is less important in 2009 than 1996

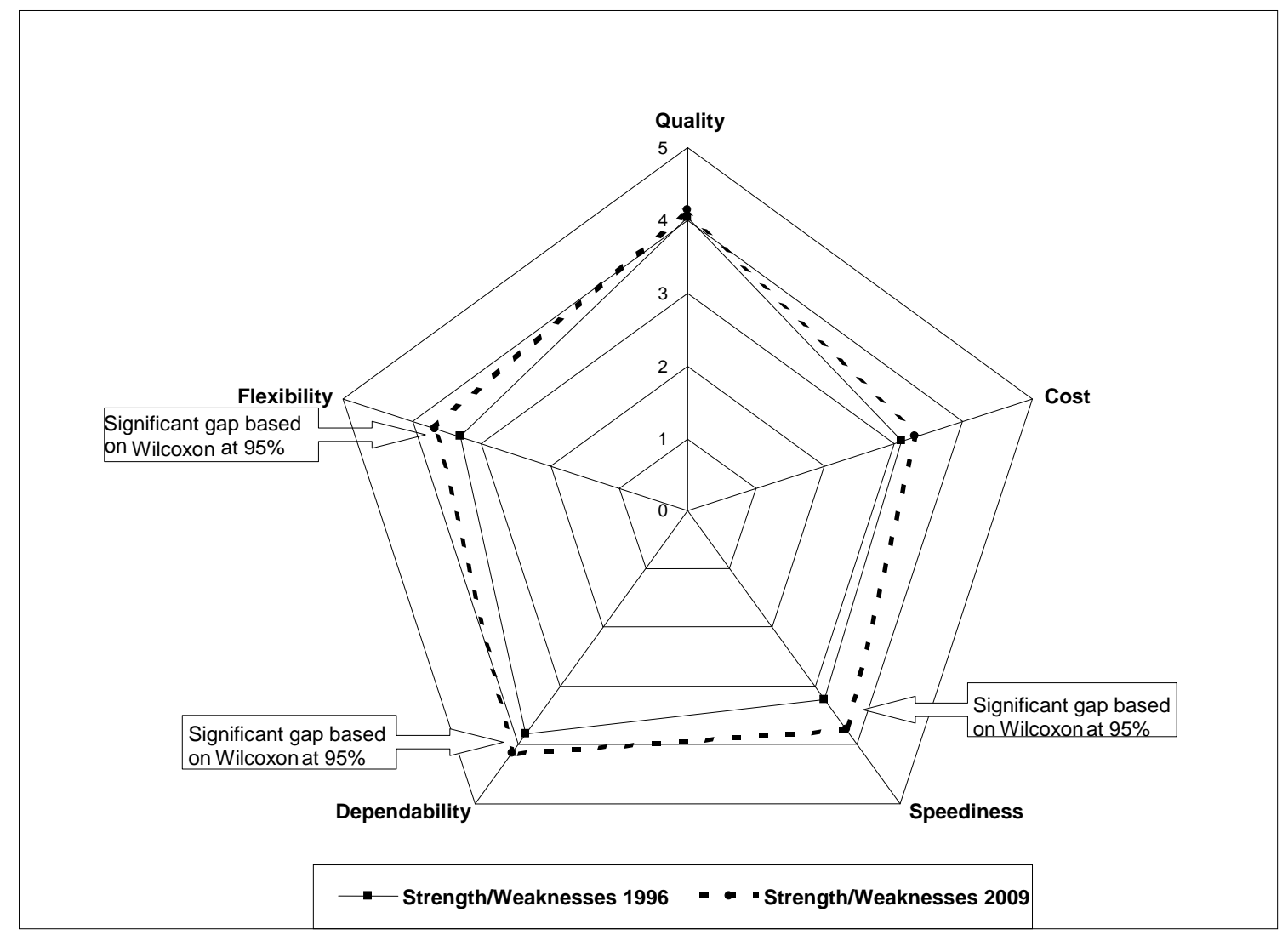

Graph 5: Current strength 1996 compared to current strength 2009

Table 12: Future importance nationally: 1996 versus 2009

\begin{tabular}{|c|c|c|c|c|c|c|c|c|c|c|}
\hline & \multicolumn{2}{|c|}{ Quality } & \multicolumn{2}{|c|}{ Cost } & \multicolumn{2}{|c|}{ Speediness } & \multicolumn{2}{|c|}{ Dependability } & \multicolumn{2}{|c|}{ Flexibility } \\
\hline & 1996 & 2009 & 1996 & 2009 & 1996 & 2009 & 1996 & 2009 & 1996 & 2009 \\
\hline Total & 129 & 104 & 129 & 104 & 127 & 104 & 128 & 104 & 127 & 104 \\
\hline Mean & 4,473 & 4,721 & 4,527 & 4,144 & 3,993 & 4,077 & 4,367 & 4,327 & 3,789 & 3,769 \\
\hline Std dev & 0,690 & 0,710 & 0,660 & 0,989 & 0,830 & 0,746 & 0,700 & 0,716 & 1,000 & 1,051 \\
\hline Rank & 2 & 1 & 1 & 3 & 4 & 4 & 3 & 2 & 5 & 5 \\
\hline Gap & \multicolumn{2}{|c|}{$+0,250$} & \multicolumn{2}{|c|}{$-0,390$} & \multicolumn{2}{|c|}{$+0,090$} & \multicolumn{2}{|c|}{$-0,040$} & \multicolumn{2}{|c|}{$-0,020$} \\
\hline $\begin{array}{l}\text { Significance } \\
\text { based on 2- } \\
\text { tailed T-test at } \\
95 \%\end{array}$ & \multicolumn{2}{|c|}{ Yes } & \multicolumn{2}{|c|}{ Yes } & \multicolumn{2}{|c|}{ No } & \multicolumn{2}{|c|}{ No } & \multicolumn{2}{|c|}{ No } \\
\hline
\end{tabular}

$+=$ belief that future importance is more important in 2009 than $1996 ;-=$ belief that future importance is less important in 2009 than 1996 


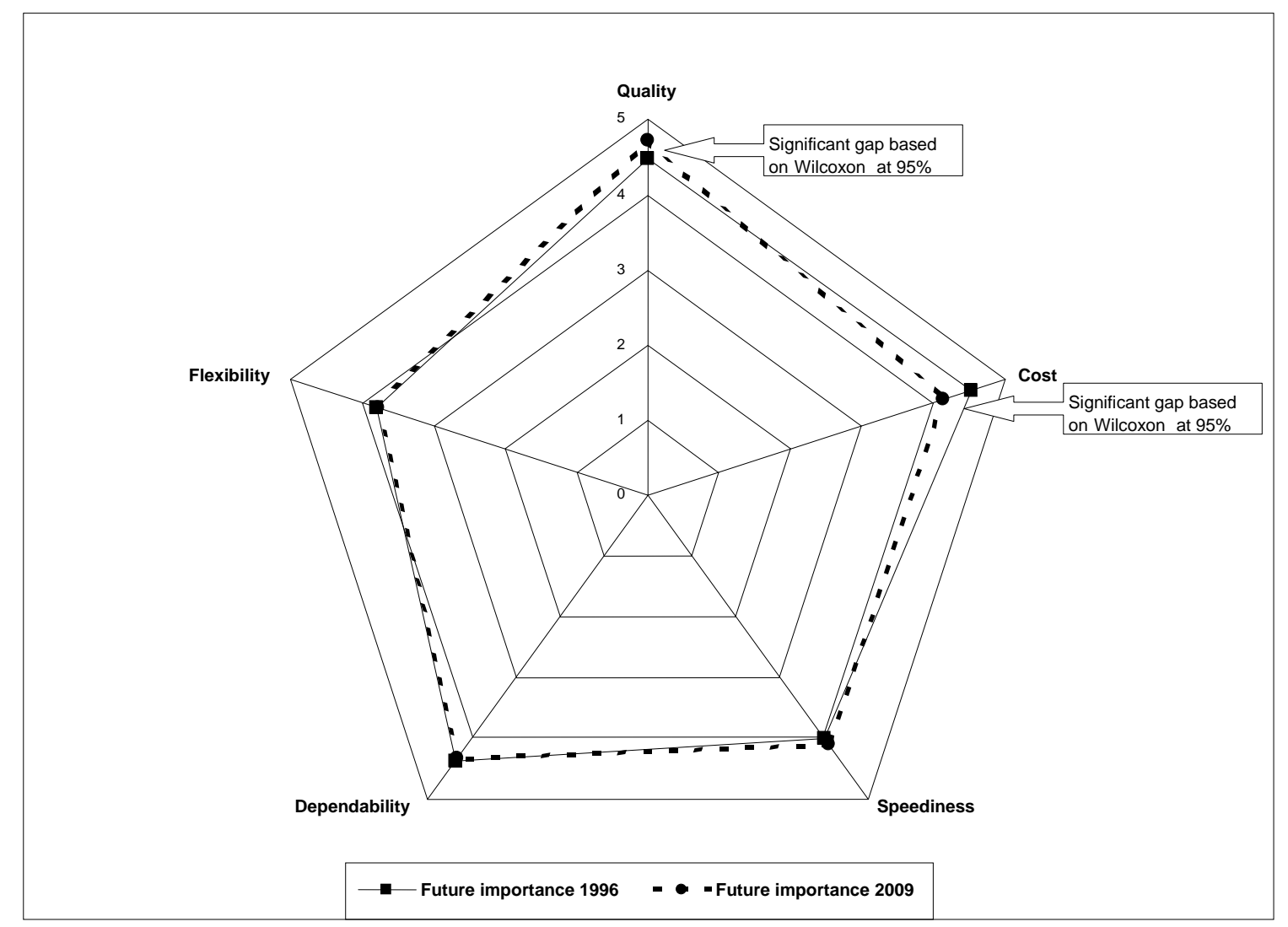

Graph 6: Future importance 1996 compared to future importance 2009: Nationally

Table 13: Future importance internationally: 1996 versus 2009

\begin{tabular}{|c|c|c|c|c|c|c|c|c|c|c|}
\hline & \multicolumn{2}{|c|}{ Quality } & \multicolumn{2}{|c|}{ Cost } & \multicolumn{2}{|c|}{ Speediness } & \multicolumn{2}{|c|}{ Dependability } & \multicolumn{2}{|c|}{ Flexibility } \\
\hline & 1996 & 2009 & 1996 & 2009 & 1996 & 2009 & 1996 & 2009 & 1996 & 2009 \\
\hline Total & 126 & 103 & 126 & 102 & 125 & 103 & 126 & 103 & 125 & 103 \\
\hline Mean & 4,721 & 4,810 & 4,650 & 4,210 & 4,184 & 3,980 & 4,540 & 4,330 & 3,976 & 4,090 \\
\hline Std dev & 0,550 & 0,506 & 0,601 & 0,904 & 0,850 & 0,077 & 0,700 & 0,820 & 1,030 & 0,910 \\
\hline Rank & 1 & 1 & 2 & 3 & 4 & 5 & 3 & 2 & 5 & 4 \\
\hline Gap & \multicolumn{2}{|c|}{$+0,090$} & \multicolumn{2}{|c|}{$-0,440$} & \multicolumn{2}{|c|}{$-0,200$} & \multicolumn{2}{|c|}{$-0,210$} & \multicolumn{2}{|c|}{$+0,110$} \\
\hline $\begin{array}{l}\text { Significance } \\
\text { based on 2-tailed } \\
\text { T-test at } 95 \%\end{array}$ & No & & Yes & & Yes & & Yes & & No & \\
\hline
\end{tabular}

$+=$ belief that future importance is more important in 2009 than 1996; - = belief that future importance is less important in 2009 than 1996 


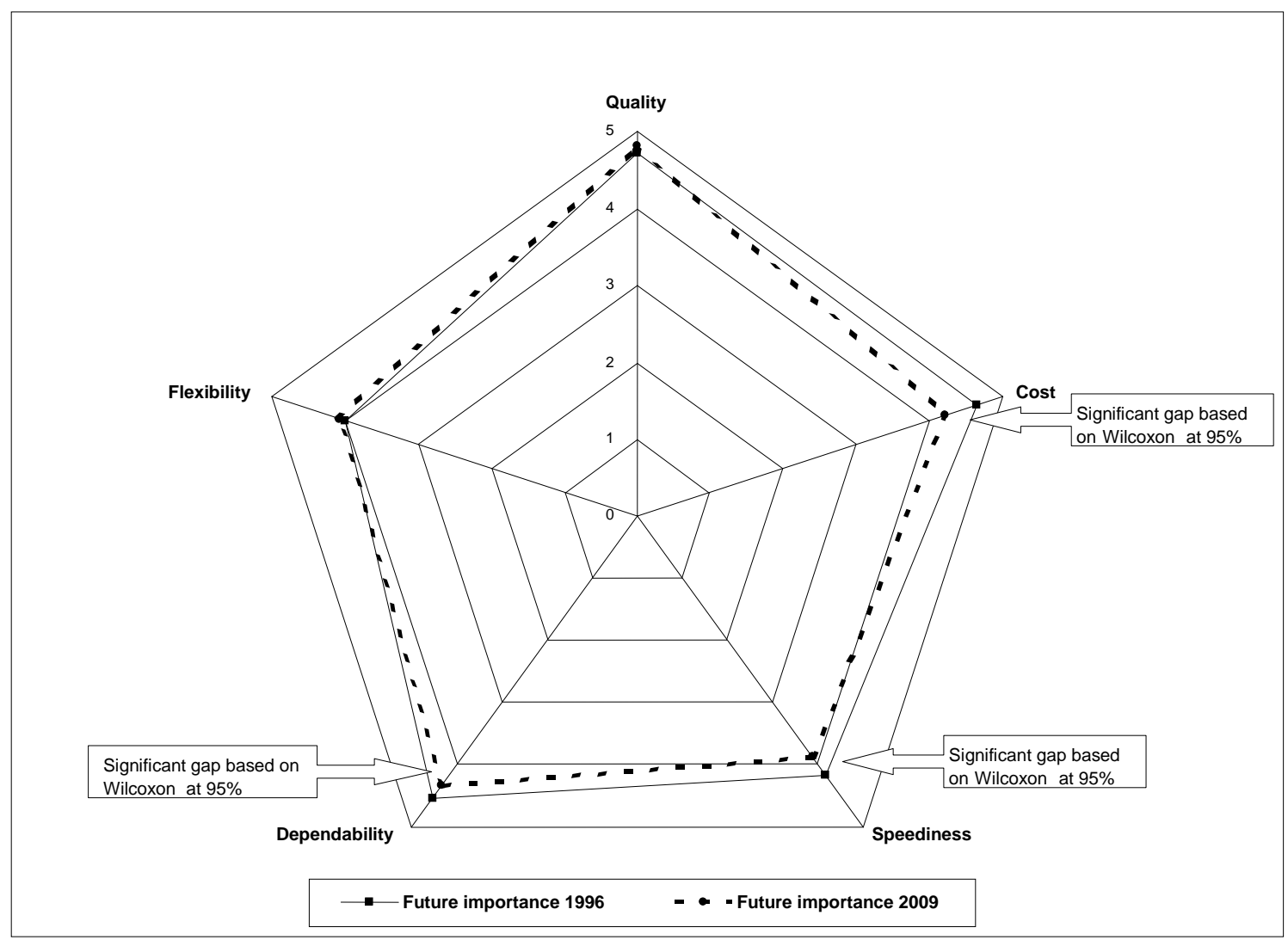

Graph 7: Future importance 1996 compared to future importance 2009: Internationally

\section{Conclusions}

Since the majority $( \pm 86 \%)$ of the respondents believe that the operations capability of their company contributes to long-term superior business performance and success, and moreover, since $97 \%$ of them believe that such capabilities will become more important in future, considered as enabling better competitiveness in both national and international markets, it is recommended that South African businesses:

- observe the following focus in terms of competitive operations priorities (in order of priority): (1) high quality; (2) high dependability; (3) low cost; (4) high speed; and (5) high flexibility, when competing against national competitors;

- $\quad$ similarly, observe the following focus in terms of COPs for competing against international competitors: (1) high quality; (2) high dependability; (3) low cost; (4) high flexibility; and (5) high speed;

- improve their current performance levels with regard to attaining (1) low cost $( \pm 26 \%)$; (2) high speed $( \pm$ $11 \%)$; and (3) higher quality $( \pm 10 \%)$, when dealing with national competitors;

- $\quad$ similarly, improve their current performance levels with regard to attaining (1) low cost $( \pm 24 \%)$; (2) higher quality ( $\pm 19 \%)$; and (3) high flexibility $( \pm 6 \%)$, when dealing with international competitors;

- Note that, with a view to better national as well as international competitiveness, offering high quality and dependability is perceived as a current strength (though high quality is also the COP which calls for the second largest improvement on average, viz. $\pm 14 \%$ ), while attaining low cost is seen as a current weakness (though low cost is also the COP calling for the largest improvement on average, viz. $\pm 25 \%$ );

- Similarly, note that high quality, dependability and low cost are believed to be the most important COPs for the purposes of future national and international competition;

- acknowledge that developing an operations capability, which offers high-quality products and/or services at a low cost on a dependable basis, appears to hold the most promise for future enhanced competition in both national and international markets;

- $\quad$ recognise (albeit with some caution) that improvements seem to have occurred since 1996 in all five of the COPs, especially concerning speediness, high flexibility and greater dependability. However, some shifts in perception regarding the future importance of COPs occurred during the interval between 1996 and 2009. High quality is considered even more important for 
national and international competition while offering low cost has surprisingly decreased in relative importance in terms of the five COPs when competing against both against national and international competitors, as compared from 1996 to 2009. Low cost in the 2009 study is the third most important focus point for both national and international competitiveness, but importantly, it needs to improve, based on the largest percentage $( \pm 25 \%)$.

\section{References}

Berry, W.L., Hill, T. \& Klompmaker, J.E. 1999. 'Aligning marketing and manufacturing strategies with the market', International Journal of Production Research, 37(16):35993618 .

Collins, R.S. \& Schmenner, R. 1993. Achieving rigid flexibility: factory focus for the 1990s. European Management Journal, 11(4): 443-447.

Corbett, L.M. 1998. 'Benchmarking manufacturing performance in Australia and New Zealand', Benchmarking for Quality Management \& Technology, 5(4):271-282.

Corbett, L.M. \& Claridge, G.S. 2002. 'Manufacturing capability elements and business performance', International Journal of Production Research, 40(1):109131.

Crowe, T.J. \& Nuño, J.P. 1991. Deciding manufacturing priorities: flexibility, cost, quality and service. Long Range Planning, 24(6): 88-95.

De Boer, I. 2009. 'Competitive operations priorities for SA businesses'. CD received on 11 August 2009 and updated report on 9 September 2009.

Evans, J.R. \& Collier, D.A.R. 2007. Operations management: An integrated goods and services approach. Mason, $\mathrm{OH}$ : Thomson.

Feurer, R. \& Chaharbaghi, K. 1995. Strategy development: past, present and future. Management Decision, 33(6): 1121.

Garvin, D.A. 1993. Manufacturing strategic planning. California Management Review, 35: 85-106.

Hayes, R.H. \& Wheelwright, S.C. 1984. Restoring our competitive edge: Competing through manufacturing. New York: Wiley.

Haynes, R.H. \& Pisano, G.P. 1994. Beyond world-class: the new manufacturing strategy. Harvard Business Review, 72: 77-86.

Hill, T. 1993. Manufacturing strategy. $2^{\text {nd }}$ Edition. London: MacMillan.

Hipkin, I. 2004. 'Determining technology strategy in developing countries', The International Journal of Management Sciences, 32:245-260.
Klein, S. \& Wöcke, A. 2007. 'Emerging global contenders: The South African experience', Journal of International Management, 13:319-337.

Krüger, L.P. 1997. 'Strategic manufacturing priorities for South African manufacturers: The need to shift emphasis and improve on current performance levels', South African Journal of Business Management, 28(4):138-146.

Miller, J.G. \& Roth, A.V. 1994. A taxonomy of manufacturing strategies. Management Science, 40(3): 285304.

Nakane, J. 1986. Manufacturing futures survey in Japan: a comparative survey 1983-1986. Research Report. Tokyo: Waseda University.

Noble, M.A. 1995. Manufacturing strategy: testing the cumulative model in multiple country context. Decision Sciences, 26: 693-721.

Russell, R.S. \& Taylor, B.W. III. 1995. Production and operations management: focusing on quality and competitiveness. Englewood Cliffs, NJ: Prentice-Hall.

Schlie, T.W. \& Goldhar, J.D. 1995. Advanced manufacturing and new directions for competitive strategy. Journal of Business Research, 33: 103-114.

Schonberger, R.J. \& Knod, E.M. Jr. 1991. Operations management: improving customer service. $4^{\text {th }}$ Edition. Homewood, IL: Irwin.

Slack, N., Chambers, S., Harland, C., Harrison, A. \& Johnston, R. 1995. Operations management. London: Pitman.

Slack, N., Chambers, S. \& Johnston, R. 2007. Operations management. $5^{\text {th }}$ Edition. Harlow, England: Pearson Education, FT Prentice-Hall.

Vickery, S.K., Droge, C. \& Markland, R.E. 1993. Production competence and business strategy: do they affect business performance? Decision Sciences, 24(2): 435-455.

Walker, M.I. \& Minnitt, R.C.A. 2006. 'Understanding the dynamics and competitiveness of the South African minerals input cluster', Resources Policy, 31:12-26.

Zahra, S.A. \& Das, S.R. 1993. Building competitive advantage on manufacturing resources. Long Range Planning, 26(2): 90-100. 